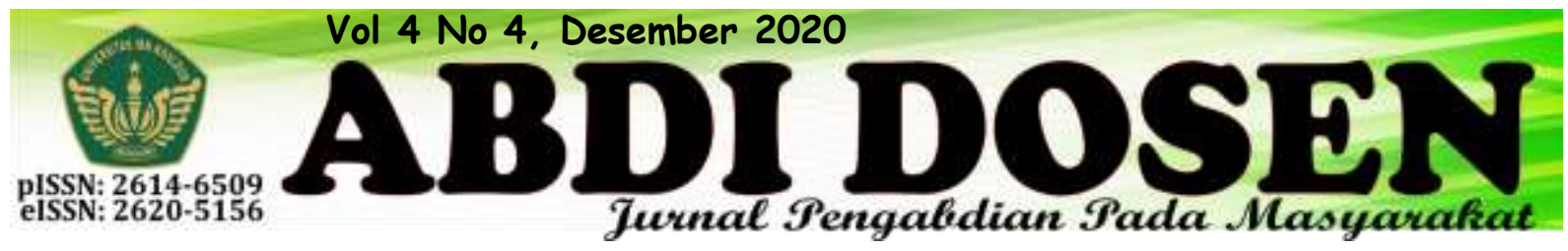

\title{
MAHASISWA DAN BUNUH DIRI: RESILIENSI MAHASISWA DALAM MENGHADAPI SKRIPSI
}

\author{
Silviana Purwanti ${ }^{1}$, Ainun Nimatu Rohmah ${ }^{2}$ \\ silvianapurwanti@gmail.com ${ }^{1 *}$, \\ ainunrom@gmail.com ${ }^{2}$ \\ Program Studi Ilmu Komunikasi, Fakultas Ilmu Sosial dan Ilmu Politik, Jl. Muara Muntai, Gn. Kelua, Kec. \\ Samarinda Ulu, Kota Samarinda, Kalimantan Timur 75411 \\ Universitas Mulawarman ${ }^{12}$
}

\begin{abstract}
ABSTRAK
Pengabdian Kepada Masyarakat yang dilaksanakan di Program Studi Ilmu Komunikasi, Fakultas Ilmu Sosial dan Ilmu Politik Universitas Mulawarman dilaksanakan secara daring dengan metode webinar. Tujuan pengabdian ini adalah memberikan penyuluhan oleh praktisi kesehatan mental kepada para dosen dan mahasiswa untuk saling harmonis agar tugas akhir atau yang biasa disebut skripsi yang belakangan dari pemberitaan media online dan offline menjadi pencetus bunuh diri di klanagan mahsiswa tingkat akhir. salah satu penyebabnya adalah pola komunikasi interpersonal yang kurang baik antara mahasiswa dan dosen dan diperkuat oleh keadaan mental mahasiswa yang merasa terbebani dan mengalami berbagai kesulitan dalam mengerjakan skripsi, karena merasa bingung memulai untuk mengerjakannya. Permasalahan dan tantangan inilah yang sering dihadapi oleh mahasiswa dalam menempuh pengerjaan skripsi. Kondisi tersebut juga didukung oleh ketahanan mahasiswa yang lemah akan tekanan untuk menyelesaikan tugas akhir tersebut dengan baik. Untuk itu kami menyelenggarakan penyuluhan kepada dosen dan mahasiswa tentang bagaimana agar dosen sebagai pembimbing dapat lebih bijak dalam penyampaian pesan kepada mahasiswa tersebut dan untuk mahasiswa lebih memiliki ketahanan yang tinggi dari dalam dirinya agar mampu bertahan menghadapi kondisi sulit dan berusaha menyelesaiakan tugas akhir. Ketahanan tersebut, biasanya juga disebut dengan istilah resiliensi akademik.
\end{abstract}

\section{Kata kunci: bunuh diri, mahasiswa, resiliensi, skripsi}

\begin{abstract}
Community service carried out in the Communication Science Study Program, Faculty of Social and Political Sciences, Mulawarman University, is carried out online using the webinar method. The purpose of this service is to provide counseling by mental health practitioners to lecturers and students. The activity aims to create harmony among lecturers and students, particularly in the process of writing the final project or thesis. Online and offline media have been discussed the thesis writing process as the trigger of suicide action among students. One of the causes is poor interpersonal communication between students and lecturers as well as the mental state of
\end{abstract}


students who feel overwhelmed by various difficulties in working on their thesis, one of which is weak resistance. Students often face these problems and challenges in completing their thesis. Therefore, we conduct counseling on how to make lecturers as mentors are as wiser as possible in conveying messages to students. As for students, this activity supports them to have more resilience from within themselves to confront difficult conditions and try to complete their final project. This resilience is also known as academic resilience.

Keywords: suicide, students, resilience, thesis

\section{PENDAHULUAN}

Para mahasiswa di Indonesia dalam fase menyelesaikan tugas akhir yaitu skripsi seringnya menjadi 'momok', karena sudah ketakutan akan proses pembimbingan dan pengerjaan skripsi yang dianggap menyeramkan. Apalagi ditambah dengan waktu pengerjaan yang terbatas atau diatur oleh sistem kurikulum akademik maksimal 7 tahun. Benjamin Franklin dalam kutipannya menuliskan tentang waktu, dan mahasiswa yang terjebak oleh waktu menjadi panik.

Dalam penjelasan beberapa tulisan menerangkan bahwa resiliensi terkait kapabilitas seseorang dalam bertahan, beradaptasi dan menghadapi masalah kehidupannya (Nugroho, 2012). Hal ini menjadi persoalan penting mengingat masa penyelesaian tugas akhir yaitu skripsi, dalam tulisannya Imandiri, Widyastuti, \& Jonosewojo (2017) menerangkan bagaimana dalam masa peralihan mahasiswa harus menghadapi emosi yang tidak stabil dan tekanan psikologis yang dapat berujung pada depresi.

Bila dipaparkan tentang kesulitan dan

\section{METODE PELAKSANAAN}

Metode Pelaksanaan kegiatan Program Pengabdian Kepada Masyarakat yang lingkupnya nasional dalam bentuk webinar kerumitan dalam pengerjaan skripsi itu adalah dalam hal mencari judul serta elemen penelitian lainnya termasuk menghadapi keterbatasan sumber pustaka, malas membaca, keterbatasan waktu, selain masalah dari dosen pembimbing seperti kesibukan, revisi, lamanya respon dan sebagainya (Imandiri et al., 2017).

Tulisan ini memaparkan kebutuhan pemahaman dan komunikasi interpersonal yang tepat dalam hubungan dan sikap dosen dan mahasiswa. Dengan demikian, dapat terbangun dimensi resiliensi sebagai pencegahan potensi bunuh diri di kalangan mahasiswa, sebagaimana cukup marak terjadi di Indonesia, termasuk di Kota Samarinda. Fenomena ini disinyalir merupakan implikasi lemahnya dimensi komunikasi interpersonal antara dosen dan mahasiswa serta resiliensi mahasiswa, serta lemahnya dimensi komprehensif pada hubungan mereka dalam upaya mengantisipasi permasalahan bunuh diri dalam proses penulisan skripsi.

series menggunakan zoom. Seri pertama disampaikan oleh dr. Yuniar $\mathrm{SpKj}$, (K) MMRS dengan materi "skripsi, depresi dan 
bunuh diri dan bagaimana lingkungan kampus bisa menjaganya". Peserta dalam webinar seri pertama dosen berjumlah 170 orang dan seri kedua disampaikan oleh dr. Azimatul Karimah SpKj. (K) FISCM.,

\section{HASIL dan PEMBAHASAN}

Pada seri 1 webinar Pengabdian Kepada Masyarakat, pemateri yaitu dr. Yuniar SpKj (K) MMRS merujuk tulisan dari Benny Prawira Siauw, ahli kajian bunuh diri (suicidolog). Pada tulisan tersebut dijelaskan fenomena depresi di usia muda, khususnya mahasiswa, di berbagai negara. Negara seperti Inggris, Amerika Serikat dan Jepang memiliki angkat bunuh diri yang tinggi sebagaimana dijelaskan oleh Kepala Koordinator Into the Light, sebuah peserta dalam webinar seri dua berjumlah 204 orang adapun materi yang diberikan dalam adalah "menjaga kesehatan mental dalam mengejar gelar" komunitas pemerhati pencegahan bunuh diri yang terbentuk pada 2013. Di Inggris, sepanjang 2016-2017 telah terjadi 95 kasus bunuh diri, sementara di Jepang sebanyak 250 anak dan remaja dalam periode yang sama. Sementara itu, di Indonesia terdapat 20 kasus bunuh diri dalam rentang Mei 2016 sampai dengan Desember 2018 yang sebagian besar diduga karena tugas dan skripsi.

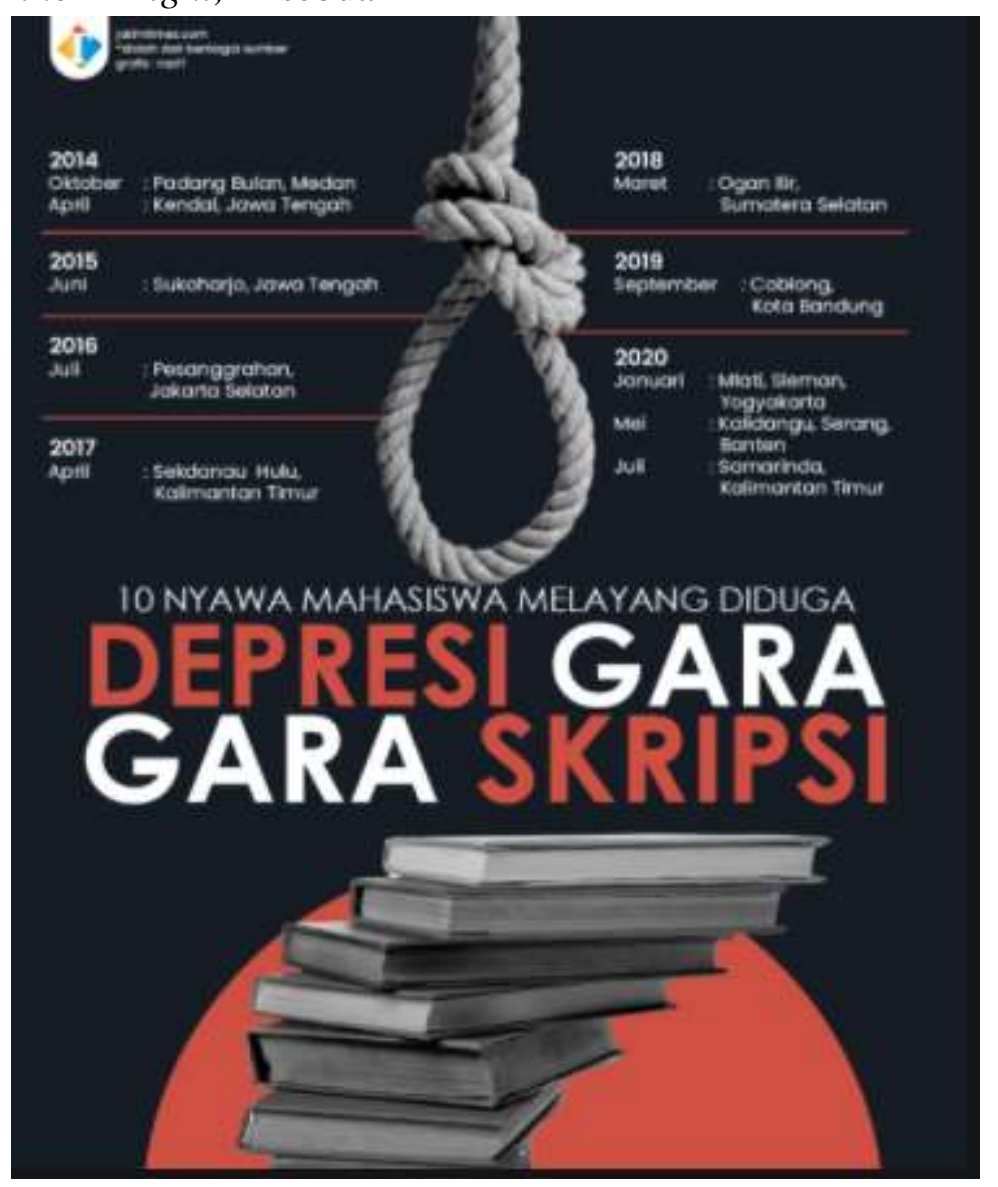

Gambar 1 Data Mahasiswa Bunuh Diri Karena Skripsi

(Sumber: jatimtimes.com) 
Menurut dr.Yuniar sebagian besar orang melakukan bunuh diri sebenarnya menunjukkan observable behavioral change, antara lain, ancaman bunuh diri, baik langsung maupun tak langsung. Pecobaan bunuh diri, perubahan perilaku, pikiran dan perasaan. Selain itu, kondisi fisik dan psikologis serta tekanan lingkungan sosial juga turut memengaruhi. Ditambah lagi kewajiban untuk menyelesaikan tugas kampus. Tekanan-tekanan tersebut akhirnya menyebabkan stress dan ketika merasa tidak sanggup menyelesaikan atau menemui permasalahan dengan dosen dan lingkungan, maka sangat rentan mengambil tindakan bunuh diri (Yusuf, 2020). Mahasiswa merupakan agen perubahan di masa depan sehingga pendidik harus memperhatikan pendidikan dan komunikasi yang tepat untuk mempersiapkan mahasiswa terjun ke masyarakat. Dengan demikian, mahasiswa dapat berkontribusi dan menciptakan perubahan sosial yang positif bagi lingkungan dan negara.

Oleh karena itu, dosen menjadi salah satu pencegah untuk mengantisipasi semakin maraknya kasus bunuh diri oleh mahasiswa. Dosen harus mengenali kararkteristik mahasiswanya, fasilitasi emotional wellbeing semua mahsiswa, jaga keterhubungan dan rasa memiliki, komunikasi dengan cara positif dan melibatkan mahasiswa dan peer groupnya dan pengawasnya baik intara maupun ekstrakurikuler (Marraccini \& Brier, 2017; Whitlock, Wyman, \& Moore, 2014).

Mahasiswa akan ada dalam lingkaran tugas, ujian, skripsi, laporan, dan ha- lain dan itu menjadi kegiatan rutin. Manajemen waktu dalam melaksanakan kegiatan perkuliahan, ekstrakulikuler, hiburan serta kepentingan keluarga dan lainnya menjadi persoalan penting untuk kalangan mahasiswa. Meskipun banyak mahasisw yang mampu menyelesaikan studi dengan baik dan sukses dalam kehidupan profesionalnya, namun terdapat sebagian mahasiswa yang justru gagal dan berakhir dengan depresi atau bunuh diri. Data WHO (2018) menunjukkan kasus bunuh diri menempati urutan kedua tertinggi penyebab kematian pada kelompk usia 15-29 tahun, selain itu setiap tahun terdapat 800.000 orang bunuh diri di berbagai belahan dunia (Susanti, 2019). Lebih lanjut, jumlah bunuh diri tertinggi adalah Korea Selatan sebesar $36.8 \%$ setiap 100.000 penduduk, dimana dari data yang sama, Indonesia berada di posisi 114 dunia Angka bunuh diri tertinggi terjadi di Korea Selatan yaitu 36,8 dari 100.000 penduduk. Sementara di Indonesia kasus bunuh diri sebesar 3,7 per 100.000 penduduk yang menempatkan Indonesia pada urutan 114 dunia (Ika, 2017).

Untuk permasalahan ini, akhirnya tanggal 10 September diperingati sebagai hari Pencegahan Bunuh Diri Sedunia. Namun, faktanya WHO (World Health Organization) dan International Association for Suicide Prevention (IASP) mencatat angka bunuh diri masih masih terbilang tinggi. Bahkan dalam kondisi tertentu, kasus bunuh diri bisa dilaporkan setiap hari.

Keinginan bunuh diri dan depresi merupakan masalah serius bagi mahasiswa. Mahasiswa didefinisikan sebagai individu yang menempuh pendidikan dan terdaftar sebagai siswa di perguruan tinggi. Secara luas, mahasiswa juga dapat diartikan sebagai agen perubahan. Mereka adalah masa depan 
bangsa yang bertanggungjawab memberikan solusi terhadap permasalahan yang dihadapi masyarakat nantinya.

Mahasiswa merupakan kaum terpelajar yang berperan dalam memajukan kehidupan bangsa. Mereka adalah intangible asset bangsa di masa depan, ketika terjadi regenerasi dalam memimpin kursi-kursi penting dalam pengelolaan negara. Nantinya, generasi tua akan digantikan oleh generasi yang saat ini berada di bangku perkuliahan. Lalu dengan pengharapan yang begitu besar kepada sosok mahasiswa mengapa mereka saat ini terlihat lemah saat menghadapi tugas akhir yaitu skripsi.

Dalam sebuah penelitian yang dilakukan Peltzer, Yi, \& Pengpid (2017) kepada pada 4.675 mahasiswa S1 dari Kamboja, Malaysia, Myanmar, Thailand, Vietnam, dan Indonesia, dengan rentang umur responden 18-23 tahun, diketahui bahwa 6,9 persen mahasiswa Yogyakarta punya pemikiran bunuh diri, salah satu terkecil di kawasan ASEAN.

Jones (1986) mengutip pendapat Durkheim yang menyatakan bahwa bunuh diri sangat terkait pada tingkat integrasi individu kepada kelompok sosial dimana individu tersebut tergabung. Artinya, bunuh diri dapat dipengaruhi oleh faktor lingkungan masyarakat dan bagaimana interaksi individu dengan lingkungannya. Mahasiswa dan kehidupan sosialnya sebagai masyarakat akan selalu berinteraksi dengan orang lain sehingga menuurt Durkheim juga dapat memengaruhi keputusan dan pola pikir mereka terhadap bunuh diri. Justifikasi tersebut yang diberikan kepada sosok seorang mahasiswa yang harus menyelesaikan skripsi sebagai syarat agar disebut sarjana maka tekanan sosial mengakibatkan mereka menjadi depresi dan pada akhirnya memutuskan untuk melakukan tindakan bunuh diri.

Sebelum Durkheim mengajukan teori penting bunuh diri, para intelektual percaya bahwa bunuh diri adalah masalah tindakan individu yang berkemauan bebas terhadap perubahan sosial dan modernitas, bukan keputusasaan pribadi (Wray, Colen, \& Pescosolido, 2011).

Meski demikian, perlu disadari pula bahwa tindakan bunuh diri tidak hanya disebabkan oleh satu penyebab. Selain masalah psikologis dan lingkungan seperti yang dijelaskan sebelumnya, rendahnya dukungan sosial juga menjadi faktor penguat seseorang melakukan tindakan itu, misalnya kekerabatan, keimanan, pekerjaan dan sebagainya (Sheila \& Videbeck, 2011). Individu yang memiliki tekanan psikologis memiliki risiko yang lebih tinggi daripada yang tidak memiliki tekanan psikologis (Forman-Hoffman et al., 2014). Itulah mengapa dibutuhkan resiliensi sebagai upaya menurunkan distress psikologis individu yang akan berpengaruh pada menurunnya kemungkinan tindakan bunuh diri (Mahmood \& Ghaffar, 2014; Pidgeon, Rowe, Stapleton, Magyar, \& Lo, 2014).

Melihat keadaan tersebut, stres atau depresi akan mempengaruhi kesehatan mental mahasiswa yang menyelesaikan tugas akhir atau skripsi jika tidak segera diatasi. Oleh karena itu, berbagai cara untuk mengatasi ketegangan saat mengerjakan skripsi juga harus terus diupayakan. Pada seri kedua webinar yang disampaikan oleh dr. Azimatul karimah, SpKJ.,(K) FSCM, yang melihat dalam perspektif psikiater bahwa mahasiswa sebaiknya membuat rencana kegiatan rutin sederhana, misalnya 
dengan membuat timeline kerja dalam penulisan skripsi, meluangkan waktu untuk istirahat yang cukup dan berkualitas, serta memberi kesempatan diri untuk bersenangsenang yang bertanggungjawab sehingga hal-hal tersebut dapat mengurangi stres.

Selain itu, mahasiswa juga dapat bergabung dengan kelompok yang saling mendukung dalam penulisan skripsi (peer group) dengan saling berbagi informasi. Selain itu, mahasiswa juga perlu mencari solusi dari tekanan atau masalah yang dirasakan selama proses pengerjaan skripsi, melalui komunikasi yang terjalin baik dengan dosen pembimbing. Begitupun dengan dosen, terutama pembimbing skripsi, di sisi lain juga harus dilatih untuk peka terhadap tanda-tanda gangguan kesehatan jiwa. Jika kondisinya tidak kunjung membaik, maka mencari pertolongan ke psikiater perlu diupayakan. Saling berkomunikasi dengan baik saat bimbingan baik online dan offline sehingga menimbulkan kenyamanan dalam diri mahasiswa tersebut. Dalam hal ini seluruh civitas akademik harus menciptakan budaya saling empati dan simpati terhadap satu

\section{SIMPULAN}

Implikasi dari webinar series 'depresi, skripsi dan bunuh diri' ini hasil yang diperoleh berdasarkan hasil diskusi via webinar yaitu mengenai rendahnya resiliensi akademik terhadap tekanan psikologis dan sosial dalam proses pengerjaan skripsi. Mahasiswa mengharapkan mendapat dosen pembimbing yang baik hati untuk membantu menyelesaikan skripsi. Sementara, dosen pembimbing juga berharap agar mahasiswa mudah memahami juka ada koreksi untuk perbaikan tulisan dalam skripsi. Lebih lanjut, sama lain sehingga sudah tidak ada lagi pemberitaan tentnag mahasiswa bunuh diri akibat tekanan dari lingkungan kampus.

Pada titik inilah keterikatan hubungan antara mahasiswa dan dosen bergantung pada kualitas komunikasi yang terbangun di antara mereka. Kualitas ini tidak hanya diperlukan namun sangat penting untuk menjaga kesehatan mental mahasiswa dan dosen. Bentuk komunikasi interpersonal sederhana yang dapat dilakukan adalah dengan memberikan perhatian dan dukungan tanpa henti. Sebagai orang yang suka berbagi cerita yang menggembirakan mampu mengurangi tingkat stres dan memberikan ketenangan psikologis. Mahasiswa sebagai manusia yang memiliki usia yang relatif muda dan sedang dalam masa transisi setelah masa remaja tentunya sangat membutuhkan dukungan moral dan emosional dari lingkungan sekitarnya. Mereka berada dalam fase transisi yang rentan terhadap pengaruh buruk dunia luar. Oleh karena itu, peran orang-orang terdekat tersebut menjadi sangat penting dalam memandang mahasiswa dan ide bunuh diri tersebut.

dosen berharap agar mahsiswa tidak terlalu santai hingga waktu akademik habis dan mendesak dosen untuk segera menyetujui hasil tulisan mereka dan akhirnya membuat para dosen menjadi sedikit emosi karena diposisikan membuat mahasiswa tersebut terlambat untuk menyelesaikan. Padahal harapan dosen pembimbing, mahasiswa mampu berupaya dan yakin untuk memperoleh hasil tulisan akhir yang baik sesuai dengan usaha-usaha yang dilakukannya. Mahasiswa dan dosen juga 
harus saling menguatkan dengan saling berpikir positif terkait penyelesaian tugas akhir tersebut, sebagai upaya kerjasama

\section{DAFTAR PUSTAKA}

\section{Buku:}

Forman-Hoffman, V. L., Muhuri, P. K., Novak, S. P., Pemberton, M. R., Ault, K. L., \& Mannix, D. (2014). Psychological distress and mortality among adults in the U.S. Household Population.

Jones, R. A. (1986). Emile Durkheim: An Introduction to Four Major Works. Beverly Hills, CA: Sage Publications, Inc.

Forman-Hoffman, V. L., Muhuri, P. K., Novak, S. P., Pemberton, M. R., Ault, K. L., \& Mannix, D. (2014). Psychological distress and mortality among adults in the U.S. Household Population.

Jones, R. A. (1986). Emile Durkheim: An Introduction to Four Major Works. Beverly Hills, CA: Sage Publications, Inc.

Peltzer, K., Yi, S., \& Pengpid, S. (2017). Suicidal behaviors and associated factors among university students in six countries in the Association of Southeast Asian Nations (ASEAN). Epub, 26, 32-38.

Sheila, L., \& Videbeck. (2011). Psychiatric Mental Health Nursing Fifth Edition. Lippincott Williams \& Wilkins. dalam menghadapi kesulitan-kesulitan yang ada dalam proses penulisan skripsi.

Whitlock, J., Wyman, P. A., \& Moore, S. (2014). Connectedness and suicide prevention in adolescents: pathways and implications. Suicide and LifeThreatening Behavior, 44, 246-272.

\section{Artikel Jurnal:}

Imandiri, A., Widyastuti, E., \& Jonosewojo, A. (2017). State Anxiety Inventory Score Among Students with Final Assignment. Journal of Vocational Health Studies, 1(1), 1-14.

Mahmood, K., \& Ghaffar, A. (2014). The relationship between resilience, psychological distress and subjective well-being among dengue fever survivors. Global Journals Inc, 14(10), $13-24$.

Marraccini, M. E., \& Brier, Z. M. F. (2017). School connectedness and suicidal thoughts and behaviors: A systematic meta-analysis. Sch Psychol Q, 32(1), 5-21.

https://doi.org/10.1037/spq0000192

Nugroho, W. B. (2012). Pemuda, Bunuh Diri dan Resiliensi: Penguatan Resiliensi sebagai Pereduksi Angka Bunuh Diri di Kalangan Pemuda Indonesia. Jurnal Studi Pemuda, 1(1).

Peltzer, K., Yi, S., \& Pengpid, S. (2017). 
Suicidal behaviors and associated factors among university students in six countries in the Association of Southeast Asian Nations (ASEAN). Epub, 26, 32-38.

Pidgeon, A. M., Rowe, N. F., Stapleton, P., Magyar, H. B., \& Lo, B. C. (2014). Examining characteristics of resilience among university students: an international study. Open Journal of Social Sciences, 2, 14-22.

Whitlock, J., Wyman, P. A., \& Moore, S. (2014). Connectedness and suicide prevention in adolescents: pathways and implications. Suicide and LifeThreatening Behavior, 44, 246-272.

WHO. (2018). Mental health: strengthening our response. Retrieved October 7, 2020, from WHO.int website: https://www.who.int/news-room/factsheets/detail/mental-healthstrengthening-our-response

Wray, M., Colen, C., \& Pescosolido, B. (2011). The sociology of suicide. Annual Review of Sociology, 37(June 2014), 505-528. https://doi.org/10.1146/annurev-soc081309-150058

\section{Website:}

Ika. (2017). Tekan Angka Bunuh Diri,
Kenali Faktor Pemicu dan Tandatandanya. Retrieved November 10, 2020, from Universitas Gadjah Mada website: https://ugm.ac.id/id/berita/14577tekan-angka-bunuh-diri-kenali-faktorpemicu-dan-tanda-tandanya

Susanti, R. (2019). Angka Bunuh Diri Tinggi, Baru 9 Persen Penderita Depresi Dapat Pengobatan Medis. Retrieved November 10, 2020, from KOMPAS.com website: https://bandung.kompas.com/read/201 9/10/14/12421151/angka-bunuh-diritinggi-baru-9-persen-penderitadepresi-dapat-pengobatan?page=all

Yusuf, A. (2020). Telaah Sistematis: Intervensi Awal Pencegahan Bunuh Diri pada Mahasiswa. Retrieved October 10, 2020, from UNAIR News website:

http://news.unair.ac.id/2020/07/06/tela ah-sistematis-intervensi-awalpencegahan-bunuh-diri-padamahasiswal

WHO. (2018). Mental health: strengthening our response. Retrieved October 7, 2020, from WHO.int website: https://www.who.int/news-room/factsheets/detail/mental-healthstrengthening-our-response 